\title{
Inherent growth advantage of (pre)malignant hepatocytes associated with nuclear translocation of pro-transforming growth
} factor $\alpha$

\author{
E Schausberger', K Hufnagl', W Parzefall', C Gerner', D Kandioler-Eckersberger², F Wrba ${ }^{3}$, M Klimpfinger ${ }^{4}$, \\ R Schulte-Hermann' and B Grasl-Kraupp*,i
}

IInstitute for Cancer Research, Medical University of Vienna, Borschkegasse 8a, A-1090 Vienna, Austria; ${ }^{2}$ University Hospital for Surgery, AKH-Vienna, Währinger Gürtel 18-20, A- 1090 Vienna, Austria; Institute for Clinical Pathology, AKH-Vienna, Währinger Gürtel 18-20, A-I090 Vienna, Austria;

${ }^{4}$ Institute for Pathology and Bacteriology, Kaiser-Franz-Josef-Spital, Kundratstraße 3, A-I I 00 Vienna, Austria

The pro-peptide of transforming growth factor $\alpha$ (proTGF $\alpha$ ) was recently found in hepatocyte nuclei preparing for DNA replication, which suggests a role of nuclear proTGF $\alpha$ for mitogenic signalling. This study investigates whether the nuclear occurrence of the propeptide is involved in the altered growth regulation of (pre)malignant hepatocytes. In human hepatocarcinogenesis, the incidence of proTGF $\alpha$-positive and replicating nuclei gradually increased from normal liver, to dysplastic nodules, to hepatocellular carcinoma. ProTGF $\alpha$-positive nuclei almost always were in DNA synthesis. Also, in rat hepatocarcinogenesis, proTGF $\alpha$-positive nuclei occurred in (pre)malignant hepatocytes at significantly higher incidences than in unaltered hepatocytes. For functional studies unaltered (GSTp ${ }^{-}$) and premalignant $\left(\mathrm{GSTp}^{+}\right)$rat hepatocytes were isolated by collagenase perfusion and cultivated. Again, DNA synthesis occurred almost exclusively in proTGF $\alpha$-positive nuclei. GSTp ${ }^{+}$hepatocytes showed an $\sim 3$-fold higher frequency of proTGF $\alpha$-positive nuclei and DNA replication than GSTP- cells. Treatment of cultures with the mitogen cyproterone acetate (CPA) elevated the incidence of proTGF $\alpha$-positive nuclei and DNA synthesis in parallel. Conversely, transforming growth factor $\beta$ I (TGF $\beta$ I) lowered both. These effects of CPA and TGF $\beta$ | were significantly more pronounced in GSTp ${ }^{+}$than in GSTp ${ }^{-}$hepatocytes. In conclusion, nuclear translocation of proTGF $\alpha$ increases in the course of hepatocarcinogenesis and appears to be involved in the inherent growth advantage of (pre)malignant hepatocytes.

British Journal of Cancer (2004) 91, 1955-1963. doi:I0.1038/sj.bjc.6602191 www.bjcancer.com

Published online 9 November 2004

(c) 2004 Cancer Research UK

Keywords: hepatocarcinogenesis; transforming growth factor $\alpha$; pro-peptide; tumour prestages; growth regulation

Hepatocellular carcinoma (HCC) is one of the most common cancers worldwide, particularly in Asia and Africa, accounting for about 1 million deaths per year (Parkin et al, 2001). Recently, its incidence has substantially increased in Europe and the United States (El-Serag and Mason, 1999; Parkin et al, 2001). Transforming growth factor $\alpha(\mathrm{TGF} \alpha)$ is one of the cytokines, causally involved in the pathogenesis of liver cancer (Kiss et al, 1997; Grisham, 2001). It is produced by hepatocytes and nonparenchymal liver cells for paracrine, autocrine and/or juxtacrine stimulation, as shown in developing, regenerating, preneoplastic and neoplastic livers of rodents and humans (Mead and Fausto, 1989; Miller et al, 1995; Grisham, 1997; Kiss et al, 1997; Yarden and Sliwkowski, 2001). Transforming growth factor $\alpha$ appears to be upregulated in all stages of liver cancer development. Single hepatocytes, infected with the hepatitis-B virus, overexpress TGF $\alpha$ due to transactivation of the TGF $\alpha$ gene by the virus (Schirmacher

*Correspondence: Dr B Grasl-Kraupp;

E-mail: bettina.grasl-kraupp@meduniwien.ac.at

Received 10 March 2004; revised 29 July 2004; accepted 30 July 2004; published online 9 November 2004 et al, 1996). Hepatocellular adenomas and carcinomas as well as childhood hepatoblastomas have been found to be rich in TGF $\alpha$, leading to elevated plasma levels of this cytokine (Yamaguchi et al, 1995; Kiss et al, 1997; Grisham, 2001).

According to textbook knowledge, TGF $\alpha$ is produced as a precursor transmembrane molecule (proTGF $\alpha$ ). The ectodomain of the pro-peptide may be shed from the cell surface, where it may bind to and activate the erbb-1 receptor, that confers the growth signal via phosphorylation cascades to the nucleus (Massagué, 1990; Yarden and Sliwkowski, 2001). Considering the upregulation of TGF $\alpha$ in human malignancies, including liver cancer, hope focuses on the possible therapeutic benefit of blocking TGF $\alpha$ evoked signal transduction on the cell surface, for example, by blockade of the receptor or of ligand-receptor interactions (Levitzki and Gazit, 1995; Mendelsohn, 1997). In a recent study, however, we have shown that hepatocytes in the intact liver and in primary culture synthesise proTGF $\alpha$ that translocates to the nucleus, where it appears to be involved in the mitogenic response of the cell (Grasl-Kraupp et al, 2002). This proposed novel pathway was induced by various different growth stimuli and is active in three different mammalian species, including humans. In mouse hepatocytes, almost all of the proTGF $\alpha$-pos nuclei were also 
positive for erbb-1 (Schausberger et al, 2003). Moreover, several very recent papers suggest that the erbb receptors 1, 3 and 4 may bypass the protein phosphorylation cascades for transducing mitogenic stimuli (Lin et al, 2001; Ni et al, 2001; Offterdinger et al, 2002). Thus, there is considerable evidence of a direct action of growth factors/growth factor receptors from the EGF/erbbreceptor family in the nucleus (Wells and Marti, 2002). The question emerges whether the nuclear occurrence of proTGF $\alpha$ is involved in the altered growth regulation of (pre)malignant cells.

Rodent liver provides excellent tools for functional studies on hepatocarcinogenesis (Pitot, 1990; Grasl-Kraupp et al, 1997; Grisham, 1997). Treatment of rats with genotoxic carcinogens, such as $N$-nitrosomorpholine (NNM), induces single initiated hepatocytes that are detectable by their selective immunoreactivity for placental glutathione-S-transferase (GSTp ${ }^{+}$cells); a considerable fraction of these cells develops to $\mathrm{GSTp}^{+}$(pre)malignancy (Grasl-Kraupp et al, 2000). Although human HCC often do not express GSTp due to epigenetic silencing of the gene, GSTp ${ }^{+}$ lesions of rats and (pre)malignant lesions in human liver show significant similarities, such as mutations of the wnt-pathway, overexpression of TGF $\alpha$, IGF-I and -II and other growth factors (Miller et al, 1995; Grisham, 1997; Yamada et al, 1999; Yang et al, 2003). Rates of replication and death of $\mathrm{GSTp}^{+}$cells, and thus overall cell turnover, are somewhat reduced in the single-cell stage, but are significantly increased from the two-cell stage onwards (Grasl-Kraupp et al, 1997, 2000). Thus, initiation causes a change in the growth-regulatory network that becomes evident after the first replication cylce of $\mathrm{GSTp}^{+}$cells. Treatment with tumour promoters, such as the progestin cyproterone acetate (CPA), or increased food intake further increases cell replication in preneoplasia, which is analogous to human hepatocarcinogenesis driven by anabolic steroids or overnutrition (Schulte-Hermann et al, 1990; Grasl-Kraupp et al, 1994; Fiel et al, 1996; Nair et al, 2002). This enhanced sensitivity of liver preneoplasia towards the various growth stimuli could result from an altered uptake, production and/or processing of endogeneous growth regulatory factors by the premalignant cell compartment.

In the present study, we asked whether the nuclear occurrence of proTGFá is involved (i) in the altered growth regulation of (pre)malignant hepatocytes and (ii) in the enhanced sensitivity of these cells towards induction of DNA replication by known growth stimulators. Recently, preneoplastic rat liver cells have become available for investigation in an ex vivo culture model (Löw-Baselli et al, 2000b). We applied this model, in combination with studies on human livers, and found that proTGF $\alpha$-positive nuclei increased in the course of hepatocarcinogenesis. The possible role of nuclear proTGF $\alpha$ for the growth advantage of (pre)malignant cells is discussed with regard to tumour-therapeutic strategies targeted at TGF $\alpha /$ erbb-1 interactions on the cell surface.

\section{MATERIALS AND METHODS}

\section{Human liver samples}

Patients suffering from dysplastic liver nodules $(n=9)$, hepatocellular adenoma $(n=3)$, or HCC $(n=10)$ were resected; chemotherapy had not been applied before surgery. Tissue samples were immediately fixed in $10 \%$ buffered formaldehyde. Classification of liver lesions and stage of disease followed published guidelines (Edmondson and Steiner, 1954; Hermank et al, 1993; International Working Party, 1995). For further details, see Table 1. Informed consent was obtained from all patients.

\section{Human hepatocyte and hepatoma cell lines}

The human hepatoma cell lines HepG2 (ATCC-No HB-8065), Hep 2B2.1-7. (ATCC-No HB-8064), and WRL 68 (ATCC-No CL-48)
Table I Age and sex of the patients, causative factors for the development of disease, histopathological diagnoses and TNM classification

\begin{tabular}{|c|c|c|c|c|}
\hline Age & Sex & Aetiology & Liver changes & Diagnosis \\
\hline 27 & $\mathrm{f}$ & Glycogenosis I & S, glycogenosis & $\mathrm{HCA}$ \\
\hline 33 & $f$ & & S & $\mathrm{HCA}$ \\
\hline 46 & f & & & $\mathrm{HCA}$ \\
\hline 39 & $\mathrm{~m}$ & & $\mathrm{~S}, \mathrm{H}$ & DN-LG \\
\hline 37 & $f$ & & $\mathrm{~S}, \mathrm{H}$ & DN-LG \\
\hline 48 & $\mathrm{~m}$ & & $\mathrm{~F}$ & DN-LG \\
\hline 25 & f & & $U$ & DN-LG \\
\hline 52 & $f$ & & U & $\mathrm{DN}-\mathrm{HG}$ \\
\hline 55 & $\mathrm{~m}$ & $\mathrm{HCV}$ & C & $\mathrm{DN}-\mathrm{HG}$ \\
\hline 61 & $\mathrm{~m}$ & $\mathrm{HCV}$ & C & $\mathrm{DN}-\mathrm{HG}$ \\
\hline 50 & $\mathrm{~m}$ & $\mathrm{HCV}$ & C & $\mathrm{DN}-\mathrm{HG}$ \\
\hline 77 & $\mathrm{~m}$ & & C & $\mathrm{DN}-\mathrm{HG}$ \\
\hline 63 & $f$ & & & $\mathrm{HCC} / \mathrm{l}, \mathrm{p} T \mathrm{I}, \mathrm{pNO}, \mathrm{pMO}$ \\
\hline 59 & $f$ & & & $\mathrm{HCC} / \mathrm{p}$, 2 , pNO, pMO \\
\hline 67 & $\mathrm{~m}$ & & C & $\mathrm{HCC} / 2, \mathrm{pT} 2, \mathrm{pNO}, \mathrm{pMO}$ \\
\hline 64 & $\mathrm{~m}$ & Ethanol & C & $\mathrm{HCC} / 2, \mathrm{pT} 3, \mathrm{pNO}, \mathrm{pMO}$ \\
\hline 68 & $\mathrm{~m}$ & & & $\mathrm{HCC} / 2, \mathrm{pT} 3, \mathrm{pNO}, \mathrm{pMO}$ \\
\hline 59 & $f$ & $\mathrm{HCV}$ & C & $\mathrm{HCC} / 2, \mathrm{pT} 3, \mathrm{pNx}, \mathrm{pM} 0$ \\
\hline 53 & $\mathrm{~m}$ & Ethanol & C & $\mathrm{HCC} / 2, \mathrm{pT} 4, \mathrm{pNO}, \mathrm{pMO}$ \\
\hline 63 & $\mathrm{~m}$ & $\mathrm{HCV}$ & & $\mathrm{HCC} / 2, \mathrm{pT} 4, \mathrm{pNO}, \mathrm{pMO}$ \\
\hline 58 & $\mathrm{~m}$ & Ethanol & C & $\mathrm{HCC} / 3, \mathrm{pT} 4, \mathrm{pN} \times, \mathrm{pMO}$ \\
\hline 77 & $f$ & & & $\mathrm{HCC} / 3, \mathrm{p} T 4, \mathrm{pNx}, \mathrm{pMx}$ \\
\hline
\end{tabular}

$m$, male; $f$, female; $\mathrm{HCV}$, hepatitis-C-virus infection; $\mathrm{C}$, cirrhosis, $\mathrm{F}$, fibrosis, $\mathrm{H}$, hepatitis; S, steatosis; U, unaltered liver parenchyma; HCA, hepatocellular adenoma; DN-LG, low-grade dysplastic nodule; DN-HG, high-grade dysplastic nodule; HCC, hepatocellular carcinoma. $\mathrm{HCC} / \mathrm{I}-3$ refers to the histopathological grading of the HCCs according to published criteria (Edmondson and Steiner, 1954). The TNM staging (tumour/node/metastasis) of the disease followed the UICC guidelines (Hermank et al, 1993).

were obtained from the American Type Culture Collection (Rockville, MD, USA). The cells were maintained in vitro at $37^{\circ} \mathrm{C}$ and $5 \% \mathrm{CO}_{2}$ in Dulbecco's minimum essential medium (DMEM) supplemented with $5 \%$ foetal calf serum, $100 \mathrm{U} \mathrm{ml}^{-1}$ penicillin and $100 \mu \mathrm{g} \mathrm{ml}^{-1}$ streptomycin (all obtained from Gibco, Life Technologies Inc., Gaitherburg, MD, USA). Once per week cells were passaged at a seed density of $1 \times 10^{6}$ cells per $25 \mathrm{~cm}^{2}$ plate.

\section{Animals and treatment}

Male SPF Wistar rats, about 3 weeks old, were obtained from the Institut für Versuchstierkunde und Genetik (Himberg, Austria). Animals were kept under standardised conditions and were fed powder diet (Altromin 1321N, Altromin, Lage, FRG). At 3 weeks before treatment, animals were adapted to rhythmic feeding (from 0900 to $1400 \mathrm{~h}$ ). This procedure synchronises DNA synthesis in the liver to a single peak per day (Grasl-Kraupp et al, 1994, 2000). After adaptation, animals were treated with a single dose of NNM (Sigma, St Louis, MO, USA; $250 \mathrm{mg}$ per $10 \mathrm{ml}$ phosphate-buffered saline per kg body weight). Phenobarbital (PB) was admixed to the powder diet and was fed to a subgroup of rats from day 4 to 17 months post-NNM. Concentrations of PB were adjusted every 14 days to provide a daily dose of $50 \mathrm{mg} \mathrm{kg}^{-1}$ body weight (LöwBaselli et al, 2000b). Animals were killed by decapitation under $\mathrm{CO}_{2}$ asphyxation. For further details, see Grasl-Kraupp et al (1994, 2000) and Löw-Baselli et al (2000a). All experiments were performed according to the 'Austrian Guidelines for Animal Care and Protection', which meet the standards required by the 'UKCCCR Guidelines for the Welfare of Animals in Experimental Neoplasia' (2nd edn.) (Workman et al, 1998).

\section{Histology}

Human and rat liver samples, fixed in $10 \%$ buffered formaldehyde, were processed as described (Grasl-Kraupp et al, 1994, 2000; 
Löw-Baselli et al, 2000a); two serial sections, $1 \mu \mathrm{m}$ thick, were cut; one of the sections was stained for GSTp (rat only) or Ki-67 (human only), the second one was stained for TGF $\alpha$.

Immunostaining for TGF $\alpha$, GSTp and Ki-67 The primary antibodies used were rabbit polyclonal IgG against rat Yp-subunit of GSTp (Biotrin International, Dublin, Eire); mouse monoclonal IgG against recombinant mature TGF $\alpha$ encompassing amino acids 39-88 (clone 213-4.4, Oncogene Science, Uniondale, NY, USA); mouse monoclonal IgG against a synthetic peptide encompassing amino acids 144-160 of the C-terminus of proTGFa (Ab-3; InnoGenex, San Ramon, CA, USA); mouse monoclonal antibody against full-length recombinant Ki-67 protein (Dianova, Hamburg, FRG).

For TGF $\alpha$ or Ki-67 staining, formaldehyde-fixed and de-waxed tissue sections were placed in a glass Coplin jar filled with $0.01 \mathrm{M}$ sodium citrate buffer, $\mathrm{pH}$ 6.0. Slides were heated for periods of $2 \mathrm{~min}$ at a maximal power setting (about $800 \mathrm{~W}$ ) and for $2 \times 2 \mathrm{~min}$ at the submaximal power setting $(600 \mathrm{~W})$. The citrate buffer reached boiling point within $2 \mathrm{~min}$ and the fluid level in the Coplin jar was topped up with distilled water between heating periods to prevent drying of the sections.

The following staining schedule was used: hydrogen peroxide to block endogenous peroxidases $(3 \%, 20 \mathrm{~min}$, room temperature); incubation with $2.5 \%$ bovine serum albumin (BSA) in TBS $(0.05 \mathrm{M}$ Tris, $0.3 \mathrm{M} \mathrm{NaCl}, \mathrm{pH} 7.6 ; 30 \mathrm{~min}$, room temperature); primary antibodies were diluted in 1\% BSA-TBS (anti-Yp: 1:5000; anti-TGF $\alpha: \quad 1: 50$; anti-Ki-67:1:50) and applied overnight at $4{ }^{\circ} \mathrm{C}$; rinsing with TBS; secondary antibodies were diluted in $2.5 \%$ BSA-TBS (biotinylated goat-anti-rabbit IgG or biotinylated rabbit-anti-mouse IgG; both 1:600, Dakopatts, Glostrup, Denmark) and were applied for $90 \mathrm{~min}$ at room temperature; rinsing with TBS was followed by incubation with streptavidin-horseradish peroxidase conjugates $(1: 300$ in TBS, $45 \mathrm{~min}$, room temperature; Dakopatts); diaminobenzidine (Sigma, St Louis, MO, USA) was used for colour development. The specificity of immunohistochemistry was confirmed by omitting the primary antibodies.

\section{Determination of DNA synthesis}

Rat liver ${ }^{3} \mathrm{H}$-thymidine $\left(6.7 \mathrm{Ci} \mathrm{mmol}^{-1}\right.$; NEN, Frankfurt, FRG) was injected into the peritoneal cavity as a single dose of $0.2 \mathrm{mCi} \mathrm{kg}^{-1}$ body weight at the daily peak of DNA synthesis between 2000 and $2100 \mathrm{~h}$ (see above). After $36 \mathrm{~h}$, animals were killed. GSTp-stained sections were coated with a solution of $1 \%$ gelatine (BioRad, Richmond, CA, USA) and 0.05\% chromalaun (Merck, Darmstadt, FRG) and were air-dried. After autoradiography, the percentage of hepatocyte nuclei in DNA synthesis was determined for at least 1000 nuclei of unaltered cells in each liver and in all nucleated cells within individual GSTp ${ }^{+}$foci (labelling index (LI)). Since interindividual variations were small, LIs obtained from different livers or foci of the same experimental group were pooled.

Human liver In order to identify human hepatocyte nuclei in the S-phase of the cell cycle, serial sections were stained for TGF $\alpha$ and $\mathrm{Ki}-67$ (see above). Individual Ki-67-positive nuclei were followed in the consecutive TGF $\alpha$-stained serial section by overlaying the two images in two microscopes linked by a bridge for overprojection (Zeiss, Germany).

\section{Primary hepatocytes}

Male SPF Wistar rats were obtained from the animal facilities of the Medical University of Vienna at the age of 3-4 weeks and were treated with a single dose of NNM $\left(250 \mathrm{mg} \mathrm{kg}^{-1}\right.$ body weight), as described above. After 21 days, livers were perfused with collagenase as described (Parzefall et al, 1989; Löw-Baselli et al, 2000b).

Treatment of primary hepatocyte cultures Cells were seeded and kept under serum-free conditions, as described (Parzefall et al, 1989; Löw-Baselli et al, 2000b). Treatment commenced $4 \mathrm{~h}$ after plating (time point 0$)$. A stock of $10 \mu \mathrm{g}(10 \mu \mathrm{l})^{-1}$ of $10 \mathrm{~mm}$ acetic acid of human recombinant mature TGF $\alpha$ (UBI, Lake Placid, NY, USA) was prepared and was added to the medium for a final concentration of $10 \mathrm{ng} \mathrm{ml}^{-1}$. Tyrphostin A25 (synonym: tyrphostin AG82; Calbiochem, La Jolla, CA, USA) was dissolved in dimethylsulphoxide (DMSO) to obtain a stock of $10 \mathrm{mg} \mathrm{ml}^{-1} ; 1 \mu \mathrm{l}$ of this stock was added per ml medium. Cyproterone acetate, a gift from Schering AG (Berlin, FRG) was dissolved in DMSO. In all experiments, the final concentration of CPA was $10 \mu \mathrm{mol}$ in $0.2 \%$ solvent. Recombinant mature TGF $\beta 1$ synthesised by $\mathrm{CHO}$ transfectants was supplied gratuitously by Bristol-Myers Squibb (Seattle, WA, USA). TGF $\beta 1$ was dissolved as described (Oberhammer et al, 1992).

Double immunostaining of culture plates for GSTp and TGF $\alpha$ Cells in culture were fixed for $90 \mathrm{~min}$ at room temperature with $4 \%$ buffered formalin according to Lillie and were then kept in distilled water at $4{ }^{\circ} \mathrm{C}$ until immunostaining. Then, the following schedule was used: hydrogen peroxide to block endogenous peroxidases $(3 \%, 20 \mathrm{~min}$, room temperature); primary antibodies were diluted in $2.5 \% \mathrm{BSA}$ in TBS $(0.05 \mathrm{M}$ Tris, $0.3 \mathrm{M} \mathrm{NaCl}, \mathrm{pH} 7.6)$ (rabbit-anti-Yp 1:5000; mouse-anti-TGF $\alpha$ 1:50; mouse-antiproTGF $1: 50$ ) and applied overnight at $4{ }^{\circ} \mathrm{C}$; rinsing with TBS; secondary antibodies were diluted in 2.5\% BSA - TBS (biotinylated goat-anti-mouse IgG or alkaline-phosphatase-labelled goat-antirabbit; both 1:600; Dakopatts) and were used for $90 \mathrm{~min}$ at room temperature; rinsing with TBS was followed by incubation with streptavidin (1:300 in TBS, $45 \mathrm{~min}$, room temperature; Dakopatts); diaminobenzidine (Sigma), 5-bromo-4-chloro-3-indolylphosphate and nitro blue tetrazolium chloride (Boehringer, Mannheim, FRG) were used for colour development. Omission of the primary antibodies served as control.

Determination of DNA replication in cultured hepatocytes Immunohistochemically stained plates were coated with $1 \%$ gelatine/ $0.05 \%$ chromalaun, air-dried, dipped into photo-emulsion (Ilford K5, Dreieich, FRG), and exposed for about $14 \mathrm{~h}$. The plates were processed with a photographical developer and fixative, and were finally dried at room temperature and mounted in Kayser's glycerine gelatine (Merck, Darmstadt, FRG). The LI was calculated as percentage of labelled hepatocyte nuclei per total number of hepatocyte nuclei counted.

\section{Two-dimensional gel electrophoresis, immunoblotting and identification of protein spots}

Nuclei and cytoplasm (postnuclear supernatant) of human hepatoma cells and of rat liver were separated according to the method of Tata, applying $2.0 \mathrm{M}$ sucrose for purification (Tata, 1974). This was followed by a nuclear matrix preparation, as has been described in detail (Gerner et al, 1998).

The electrophoretically separated proteins were transferred onto PVDF sheets; the filters were soaked in excess blocking buffer (( $3 \%$ BSA, Sigma, St Louis, MO, USA) in TBST buffer ( $10 \mathrm{~mm}$ Tris-HCl, pH 8, $150 \mathrm{~mm} \mathrm{NaCl}, 0.1 \%$ Tween 20$)$ ). The mouse monoclonal antisera against amino acids 39-88 of mature TGF $\alpha$ (Oncogene Science, Ab-1, clone 134A-2B3; 1:300) were diluted in TBST buffer and were incubated overnight at $4{ }^{\circ} \mathrm{C}$. Thereafter, sheets were incubated for $1 \mathrm{~h}$ at room temperature with an alkaline phosphatase-conjugated anti-mouse IgG (Promega, Madison, WI, USA) diluted 1:7000 in TBST buffer containing 
0.25\% BSA; 5-bromo-4-chloro-3-indolylphosphate and nitro blue tetrazolium chloride (Boehringer, Mannheim, FRG) were used for staining.

For mass spectrometry fingerprinting, Coomassie Blue-stained proteins were directly cut out of preparative gels. Matrix-assisted laser desorption ionisation-time-of-flight (maldi-tof) of tryptic protein hydrolysates and protein identification were carried out essentially as described (Fountoulakis and Langen, 1997; Grasl-Kraupp et al, 2002). Proteins were considered identified by means of mass spectrometry fingerprinting when at least $15 \%$ of the whole sequence gave hits and when the molecular mass/pI values were identical to the ones calculated or published in $2 \mathrm{D}$ databases.

\section{Statistics}

If not stated otherwise, data of at least three animals per time point and treatment group are given. Where indicated, the significance of differences of means was calculated by Kruskal-Wallis test or Wilcoxon test. For incidences, confidence intervals were calculated for $P<0.05$.

\section{RESULTS}

The pro-peptide of TGF $\alpha$ is present in the nuclei of human and rat hepatocytes and human hepatoma cell lines

In anti-TGF $\alpha$-stained liver sections, immunoreaction was found within the cytoplasm, cell membranes and, most prominent, the nuclei of hepatocytes (Figure 1B, C and E). Likewise, the nuclei of the hepatoma cell lines HepG2 (Figure 1F), WRL68 and Hep2B (not shown) displayed a strong immunoreaction. Nuclear matrices, prepared from human HepG2 cells (Figure 2A) and from rat liver (Figure $2 \mathrm{~B}$ ), were separated by two-dimensional gel electrophoresis and were subsequently subjected to anti-TGF $\alpha$ immunoblotting; four spots around $17 \mathrm{kDa}$ and an isoelectric point of 7.5 appeared. Spots 1-4 of HepG2 cells were subjected to maldi-tof analysis: spot 1 was verified to be the wild-type form of proTGF $\alpha$; spot 2 was recently found to be wild-type proTGF $\alpha$ as well (Grasl-Kraupp et al, 2002). Spots 3 and 4 could not yet be identified. Immunostaining with antisera against the C-terminus of the pro-peptide also confirmed the presence of proTGF $\alpha$ in hepatocyte nuclei (see below). The mature form of TGF $\alpha$ at about $5.6 \mathrm{kDa}$ was not detected.
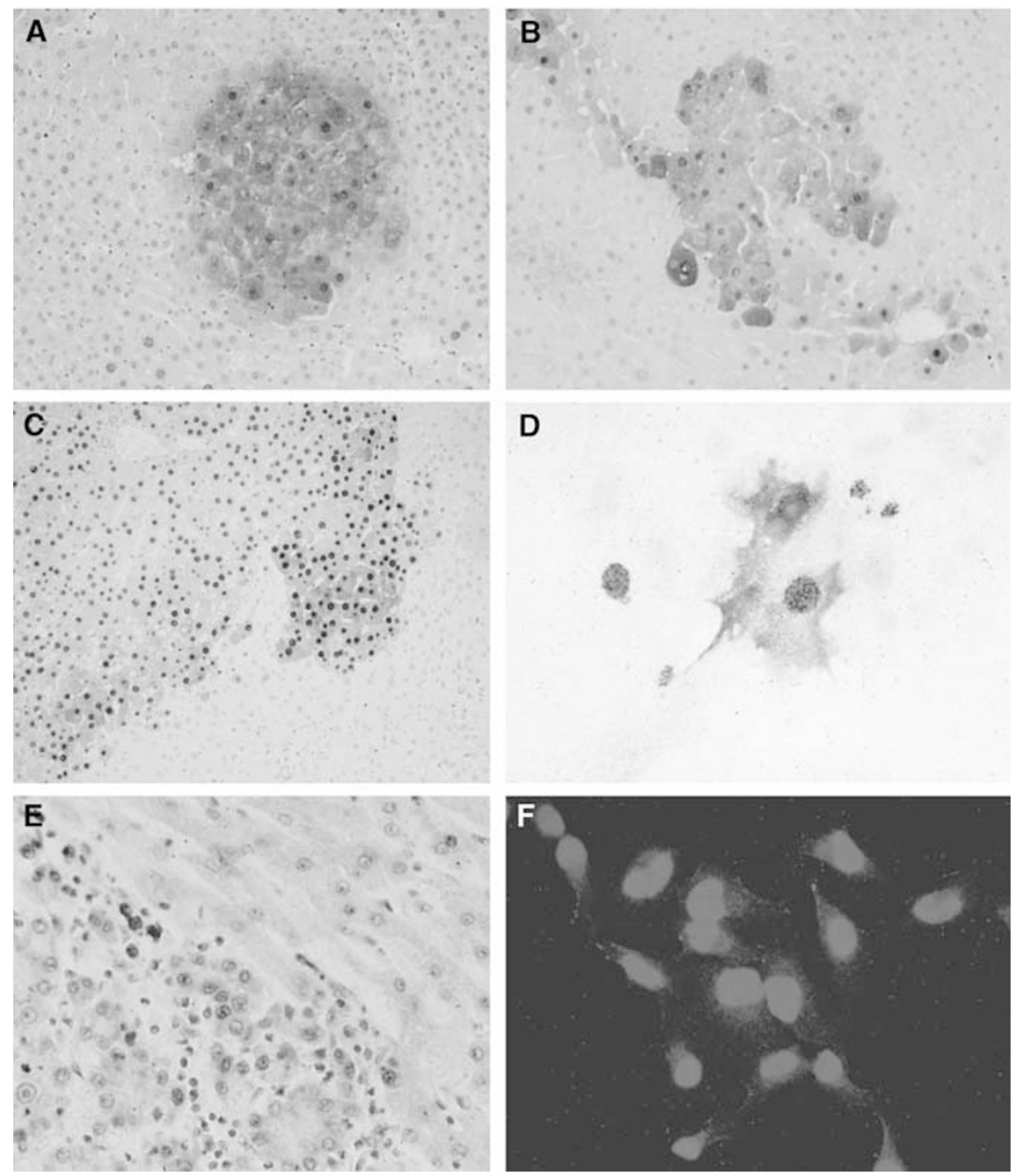

Figure I Occurrence of nuclear proTGF $\alpha$ in human and rat hepatocarcinogenesis. (A-C) Rat liver 12 months post-NNM: serial sections of a preneoplastic lesion stained for GSTp (A) and TGF $\alpha(\mathbf{B})$; (C) HCC with proTGF $\alpha$-pos nuclei (C). (D) Preneoplastic GSTp ${ }^{+}$hepatocytes (violet) with proTGF $\alpha$-pos nucleus (brown) and incorporated ${ }^{3} \mathrm{H}$-thymidine (black spots) in primary culture; hepatocytes were isolated at day $2 \mathrm{I}$ post-NNM and cultured for $48 \mathrm{~h}$; ${ }^{3} \mathrm{H}$-thymidine was added to the medium $24 \mathrm{~h}$ before harvesting. (E) Human HCC and (F) human HepG2-hepatoma cells with proTGF $\alpha$-pos nuclei. Magnifications: $\times 50$ for $(\mathbf{A}),(\mathbf{B}), \times 75$ for $(\mathbf{E}) ; \times 25$ for $(\mathbf{C}) ; \times 200$ for $(\mathbf{D}, \mathbf{F})$. 
A

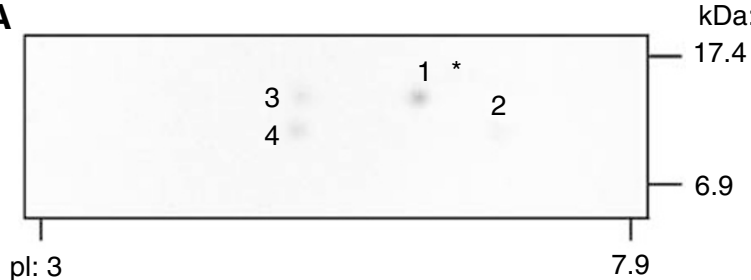

B

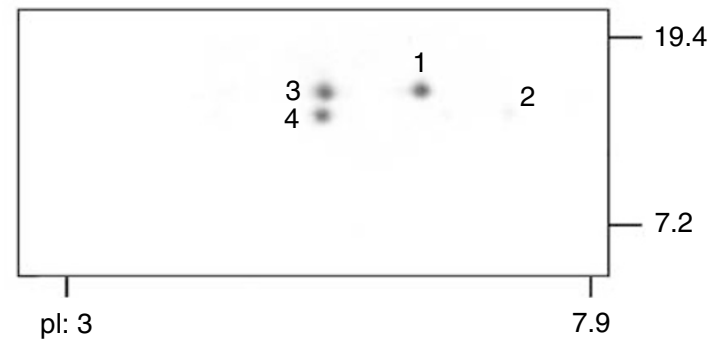

\section{*)Masses submitted/matched 2179.04/2179.04 \\ $1262.70 / 1262.56$ \\ Peptide sequence FLVQEDKPACVCHSGYVGAR GRTACCHSETVV}

Figure 2 Detection of proTGF $\alpha$ in the nuclear fraction of human HepG2-hepatoma cells and of rat liver. Nuclear matrix proteins of hepatoma cells $(\mathbf{A})$ and of an untreated male rat liver $(\mathbf{B})$ were subjected to two-dimensional immunoblotting. The gels covered a range of pl 3-8 and $\mathrm{Mr}$ 4-40 kDa. (A) Spots I-4 were analysed by maldi-tof: spot I was identified as wild-type proTGF $\alpha$; $*$ indicates the amino-acid sequence identified, which covers $19 \%$ of the total pro-peptide of TGF $\alpha$.

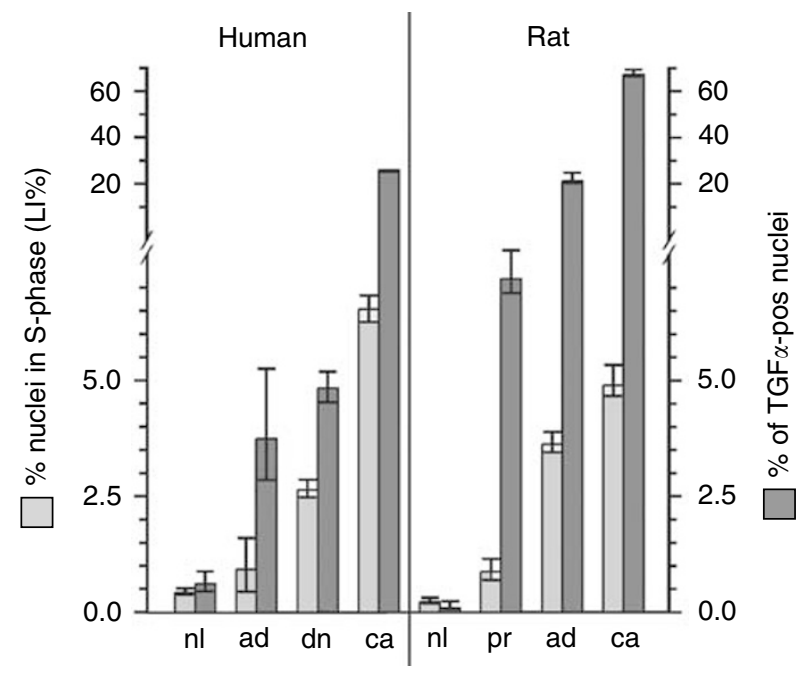

Figure 3 Increased cell replication and incidences of proTGF $\alpha$-pos nuclei in human and rat hepatocarcinogenesis. White columns represent the percentage of nuclei in S-phase (LI\%), dark columns the percentage of proTGF $\alpha$-pos nuclei. Humans: three hepatocellular adenomas, nine dysplastic nodules, 10 heptocellular carcinomas and the surrounding liver of the 22 cases were evaluated. At least 1000 hepatocyte nuclei (on average 2055 nuclei) per liver or tumour were screened for Ki-67 and proTGF $\alpha$ positivity. Rats: time interval between ${ }^{3} \mathrm{H}$-thymidine injection and killing was $36 \mathrm{~h}$. The percentages of proTGF $\alpha$-pos nuclei and LI were determined at least in: 2000 nuclei of GSTp ${ }^{-}$and 1221 nuclei of GSTp ${ }^{+}$ hepatocytes per liver $(n=13)$; I 38 I nuclei per adenoma $(n=15)$; 1362 nuclei per carcinoma $(n=14)$. nl, normal liver; pr, preneoplastic GSTp ${ }^{+}$ lesion; ad, hepatocellular adenoma; dn, dysplastic nodule; ca, HCC. Incidences are given; vertical lines give $95 \%$ confidence intervals: no overlap indicates a statistically significant difference for $P<0.05$.
Occurrence of DNA replication and nuclear proTGFa in the different stages of human hepatocarcinogenesis

The percentage of both, replicating nuclei and proTGF $\alpha$-pos nuclei, was gradually increased from normal liver, to hepatocellular adenoma, to dysplastic nodules, to HCC (Table 1, Figure 3). In unaltered liver, replicating nuclei and proTGFo-pos nuclei occurred at a similar frequency. Premalignant and malignant liver lesions, however, revealed a much higher percentage of proTGF $\alpha$ pos nuclei when compared to nuclei in S-phase (Figure 1E and 3). Staining for Ki-67 was used to identify hepatocyte nuclei in the Sphase of the cell cycle (for details, see Materials and methods); five HCC were studied: $77.3 \pm 9.2 \%$ of $343 \mathrm{Ki}-67$-positive hepatocyte nuclei evaluated displayed proTGF $\alpha$. A high co-incidence of DNA synthesis and proTGFa was recently shown also for hepatocyte nuclei in cirrhotic liver (Grasl-Kraupp et al, 2002). Taken together, these findings indicate that a hepatocyte nucleus undergoing DNA replication almost always contains proTGF $\alpha$. Further expression of proTGFa in nuclei not immediately undergoing DNA synthesis occurs predominantly in premalignant and malignant hepatocytes.

Occurrence of DNA replication and nuclear proTGF in the different stages of rat hepatocarcinogenesis

Hepatocarcinogenesis was induced in rats by application of NNM. This leads to the formation of single $\mathrm{GSTp}^{+}$cells and small preneoplastic GSTp ${ }^{+}$lesions, followed by expansive growth of some of the lesions. To enhance the formation of liver tumours, rats were treated with the tumour promoter PB (Löw-Baselli et al, $2000 \mathrm{~b})$. Analogous to the findings in human liver, $p r o T G F \alpha-$ positive nuclei occurred in (pre)malignant hepatocytes at a significantly higher incidence than in unaltered hepatocytes (Figures $1 \mathrm{~A}-\mathrm{C}$ and 3). This substantiates that the experimental model fits the human situation.

\section{Inherent growth advantage of cultured preneoplastic} $\mathrm{GSTp}^{+}$rat hepatocytes associated with nuclear proTGFa

To study the functional significance of nuclear proTGF $\alpha$ for hepatocarcinogenesis, unaltered GSTp ${ }^{-}$and preneoplastic GSTp ${ }^{+}$ cells were isolated from the livers by collagenase perfusion and cultivated. Cell isolation was performed on day 21 post-NNM treatment (no PB promotion). At this time point, there is the maximal occurrence of GSTp ${ }^{+}$cell clones in the liver. Based on stereological calculations of the size distribution in the third dimension, only $23 \pm 11 \%$ of the isolated GSTp ${ }^{+}$cells in culture derive from single-cell clones and $77 \pm 29 \%$ derive from small foci (three cells on average), with an inherently elevated cell turnover (DeGunst and Luebeck, 1998; Grasl-Kraupp et al, 2000).

Replicative DNA synthesis was generally high in the isolated hepatocytes (Figure 4); this may be explained by the fact that the livers still underwent regeneration, as observed in vivo (GraslKraupp et al, 2002). ProTGF $\alpha$ was present in the nuclei of about $10 \%$ of the hepatocytes in primary culture (Figure 4 and Table 2). In any case, DNA replication occurred preferentially in proTGF $\alpha$ pos nuclei in both GSTp ${ }^{-}$and GSTp ${ }^{+}$hepatocytes (Table 2). This was also confirmed by immunostaining of parallel culture plates with two different antisera: DNA was synthesised by $76.5 \pm 6.8 \%$ of the nuclei being positive for amino acids $39-88$ of proTGFa (encompassing the mature form) and by $65.3 \pm 19.2 \%$ of the nuclei being positive for amino acids $144-160$ of the C-terminus of the pro-peptide. In both stains, DNA synthesis in negative nuclei was a rare event (see also Table 2).

$\mathrm{GSTp}^{+}$cells showed an about three-fold higher frequency of proTGF $\alpha$-pos nuclei and DNA replication than $\mathrm{GSTp}^{-}$cells (Figure 4 and Table 2). Thus, the inherent growth advantage of the cultured preneoplastic cell population appears to be highly associated with the enhanced nuclear translocation of proTGF $\alpha$. 


\section{Different signal transduction pathways of $T G F \propto$ gene products in GSTp ${ }^{-}$and GSTp ${ }^{+}$hepatocytes}

We have confirmed recently that in our system mature TGF $\alpha$ acts via erbb-1 in the cellular membrane of proTGF $\alpha$-neg cells according to classical concepts of growth signal transduction (Grasl-Kraupp et al, 2002). Accordingly, in the present study, addition of mature TGF $\alpha$ increased DNA synthesis almost exclusively in the GSTp ${ }^{-}$cells that do not express proTGF $\alpha$. This increase in DNA synthesis was blocked by the erbb-1-tyrosine kinase inhibitor tyrphostin A25 (Figure 5). However, mature TGF $\alpha$ exerted no significant effect on any cell with nuclear proTGF $\alpha$, which was most evident for the proTGF $\alpha$-rich GSTp ${ }^{+}$population (Figure 5). At present, it is unclear why TGF $\alpha$ exerted no effect on the GSTp ${ }^{+}$cells with proTGF $\alpha$-neg nuclei. The expression of yet unidentified growth factors may confer autonomy from exogeneous growth stimuli to this subpopulation of premalignant cells. Taken together, these findings suggest that two different TGF $\alpha$ mediated signal transduction pathways are operative in different cell populations: the 'classical' erbb-1-mediated pathway of mature TGF $\alpha$ becomes active mostly in the proTGF $\alpha$-poor GSTp hepatocytes, while the second one, triggered by nuclear proTGF $\alpha$, is effective in the proTGF $\alpha$-rich preneoplastic $\mathrm{GSTp}^{+}$cells.

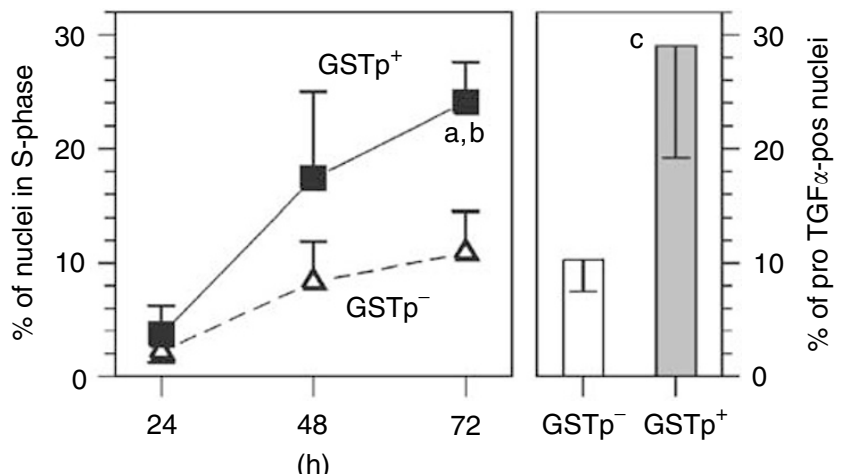

Figure 4 DNA synthesis (LI(\%)) and \% of proTGF $\alpha$-pos nuclei in cultured GSTp ${ }^{-}$and GSTp ${ }^{+}$hepatocytes. ${ }^{3} \mathrm{H}$-thymidine was added $24 \mathrm{~h}$ before harvesting of cells. The \% of proTGF $\alpha$-pos nuclei was determined after $48 \mathrm{~h}$ of culture. Symbols: $\Delta$ or open columns, GSTp ${ }^{-}$cells; $\mathbf{a}$ or dark columns, GSTp ${ }^{+}$cells. In each of the experiments, 2000 nuclei of GSTp cells and 600 nuclei of GSTp ${ }^{+}$cells were evaluated. Means \pm s.d. are given from separate experiments with cultures from five rats. Statistics of LI(\%) in GSTp $^{-}$vs GSTp ${ }^{+}$cells over time-course by Kruskal-Wallis test: (a) $P<0.00$ I. Statistics of LI(\%) in GSTp ${ }^{-}$cells vs GSTp ${ }^{+}$cells at the last time point of evaluation by Wilcoxon's test: (b) $P<0.01$. Statistics of $\%$ of proTGF $\alpha$-pos nuclei in GSTp ${ }^{-}$vs GSTp ${ }^{+}$cells by Wilcoxon's test: (c) $P<0.00$ l.
Transforming growth factor- $\beta 1$ reduces DNA synthesis and nuclear proTGF $\alpha$ in cultured GSTp ${ }^{-}$and GSTp hepatocytes

DNA replication was suppressed by 1 ng of TGF $\beta 1$ and even more by $3 \mathrm{ng}$ of TGF $\beta 1 \mathrm{ml}^{-1}$ medium in GSTp ${ }^{-}$and $\mathrm{GSTp}^{+}$cells (Figure 6). DNA replication was inhibited at the most effective concentration of the cytokine in about $66 \%$ of the GSTp ${ }^{-}$cells, but in at least $90 \%$ of the GSTp ${ }^{+}$cells. These data suggest that TGF $\beta 1$ acts more strongly on GSTp ${ }^{+}$than on $\mathrm{GSTp}^{-}$cells. Furthermore, TGF $\beta 1$ diminished the fraction of hepatocytes expressing nuclear proTGF $\alpha$ and synthesising DNA (Figure 6 and Table 2). Apparently, the suppression of DNA synthesis by TGF $\beta 1$ in primary hepatocytes involves downregulation of nuclear proTGF $\alpha$. This effect was evident for both, $\mathrm{GSTp}^{-}$and $\mathrm{GSTp}^{+}$cells.

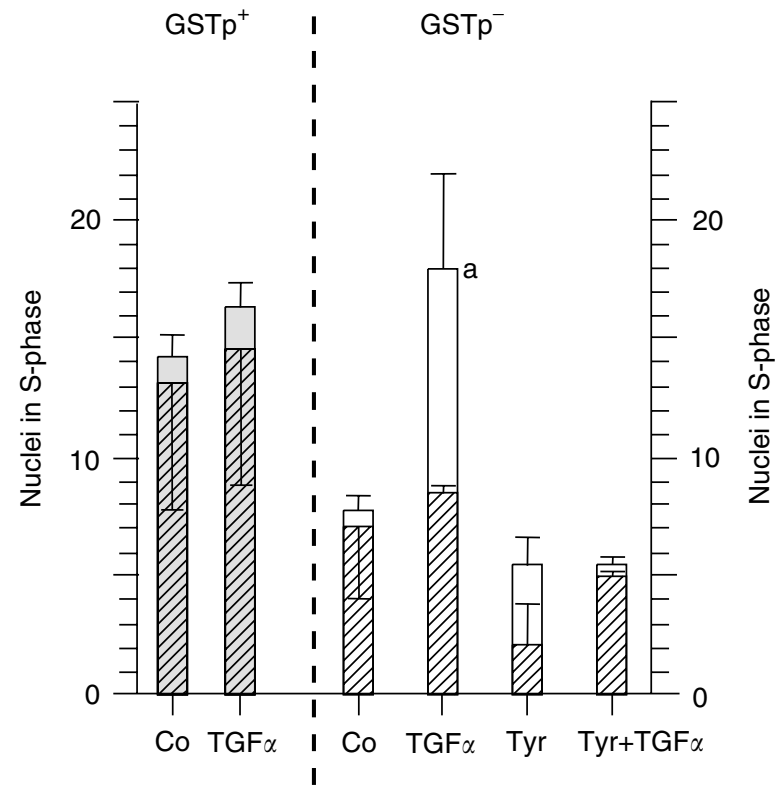

\begin{tabular}{|l|l|}
\hline \% of pro TGF $\alpha$-pos & \% of pro TGF $\alpha$-pos \\
$\square$ pro TGF $\alpha$-neg & $\square$ pro TGF $\alpha$-neg
\end{tabular}

Figure 5 Mature TGF $\alpha$ increases the percentage of nuclei in S-phase (LI\%) preferentially in GSTp ${ }^{-}$hepatocytes without nuclear proTGF $\alpha .{ }^{3} \mathrm{H}$ thymidine was added $24 \mathrm{~h}$ before harvesting of cells. The percentages of replicating and of proTGF $\alpha$-pos nuclei were determined after $48 \mathrm{~h}$ of culture. For the number of experiments and cells scored, see Figure 4. Hatched portions of the bars indicate $\mathrm{LI}$ of proTGF $\alpha$-pos nuclei; nonhatched portions of the bars indicate LI of proTGF $\alpha$-neg nuclei; the sum of the hatched and unhatched portion (total bar) indicates $\mathrm{LI}$ of all nuclei; Co: DMSO-control; TGF $\alpha$ : mature TGF $\alpha$; Tyr: Tyrphostin A25. Statistics by Student's t-test: (a) $P<0.05$.

Table 2 DNA synthesis occurs preferentially in proTGF $\alpha$-pos nuclei

\begin{tabular}{|c|c|c|c|c|c|c|}
\hline & \multicolumn{2}{|c|}{ co } & \multicolumn{2}{|c|}{ CPA } & \multicolumn{2}{|c|}{ TGF $\beta$ I ( $10 \mathrm{ng})$} \\
\hline & In GSTp- & In GSTp ${ }^{+}$ & In GSTp- & In GSTp ${ }^{+}$ & In GSTp- & In GSTp ${ }^{+}$ \\
\hline
\end{tabular}

${ }^{3} \mathrm{H}$-thymidine was added $24 \mathrm{~h}$ before harvesting of cells. The percentage of nuclei in $\mathrm{S}$ phase and of proTGF $\alpha$-pos nuclei were determined after $48 \mathrm{~h}$ of culture. In each experiment, 2000 nuclei of GSTp cells and 600 nuclei of GSTp ${ }^{+}$cells were evaluated. Means \pm s.d. are given from separate experiments with cultures from five rats. Statistics by Wilcoxon's test for GSTp- cells vs GSTP ${ }^{+}$cells. $* * * * P<0.05$, $* * * *<<0.0$ I, $* P<0.00$ I; for Co vs treated group: $* * * * * P<0.05, * * P<0.01$. 


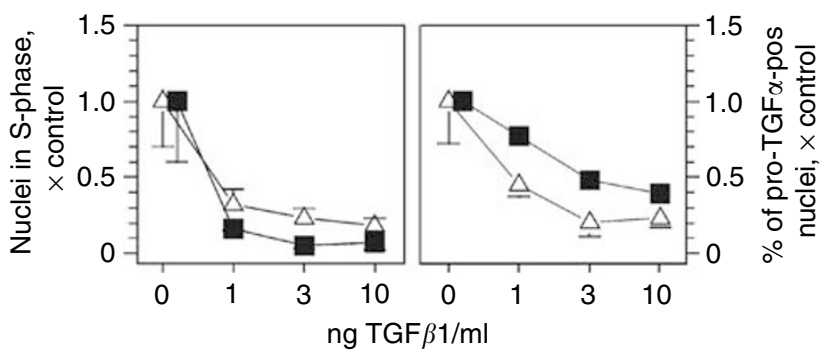

Figure 6 Transforming growth factor $\beta$ | reduces DNA synthesis and proTGF $\alpha$-pos nuclei in GSTp ${ }^{-}$and GSTp ${ }^{+}$cells cultured for $48 \mathrm{~h}^{3}{ }^{3} \mathrm{H}$ thymidine was added $24 \mathrm{~h}$ before harvesting of cells. Symbols: $\Delta$, GSTp cells, $\mathbf{\square}$, GSTp $^{+}$cells. Data are calculated as fold control; absolute values are given in Table I; number of experiments and cells scored see Figure 4. Means \pm s.d. are given. Statistics by Kruskal-Wallis test for dose-response effects within a cell population: (a) $P<0.0$ I; (b) $P<0.05$.
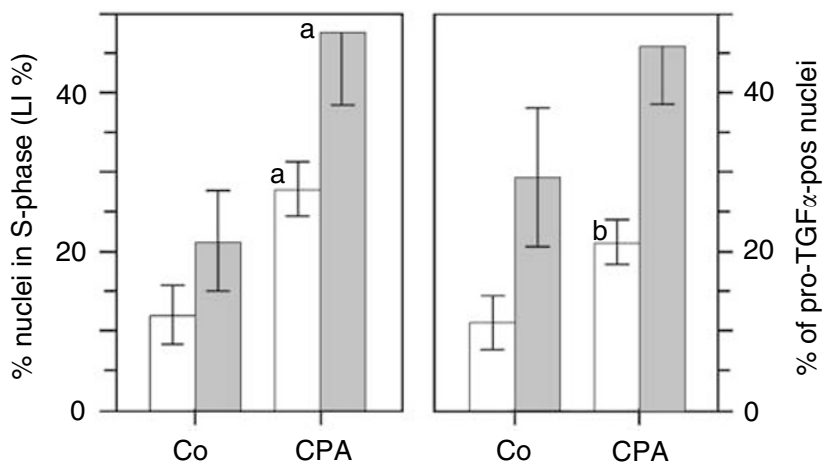

Figure 7 Cyproterone acetate induces DNA synthesis and proTGF $\alpha$ pos nuclei in GSTp ${ }^{-}$and GSTp ${ }^{+}$cells cultured for $48 \mathrm{~h}^{3}{ }^{3} \mathrm{H}$-thymidine was added $24 \mathrm{~h}$ before harvesting of cells. Symbols: light columns, GSTp ${ }^{-}$cells; dark columns, GSTp ${ }^{+}$cells. For the number of experiments and cells scored, see Figure 4. Means \pm s.d. are given. Statistics by Wilcoxon's test for Co vs CPA: (a) $P<0.0$ I; (b) $P<0.05$.

\section{The hepatomitogen CPA induces DNA synthesis and nuclear proTGF $\alpha$ in GSTp ${ }^{-}$and GSTp ${ }^{+}$hepatocytes}

Treatment with the hepatomitogen CPA doubled the LI in cultured $\mathrm{GSTp}^{-}$and GSTp ${ }^{+}$cells (Figure 7). Thus, every fifth GSTp ${ }^{+}$cell was stimulated to DNA synthesis by CPA, while only every tenth $\mathrm{GSTp}^{-}$cell was recruited to the pool of replicating hepatocytes. We asked whether nuclear proTGF $\alpha$ might be involved in this enhanced growth stimulation of the preneoplastic cell population. In fact, the CPA-induced increases in DNA synthesis were closely paralleled by an equal elevation of proTGFa-pos nuclei (Figure7 and Table 2). This may indicate that the enhanced occurrence of nuclear proTGF $\alpha$ in liver preneoplasia may commit the preneoplastic cells for preferential response towards growth stimulation.

\section{DISCUSSION}

The present paper describes that the pro-form of TGF $\alpha$ occurs in the nucleus of (pre)malignant rat and human hepatocytes, while mature TGF $\alpha$ was not detected. The translocation of proTGF $\alpha$ to the nucleus may contribute to the inherent growth advantage of early and late stages of hepatocarcinogenesis. The present observations extend recent findings on normal hepatocytes from rat, mouse and humans, which revealed that the translocation of proTGFa to the nucleus in G1 of the cell cycle is almost always followed by replicative DNA synthesis (Grasl-Kraupp et al, 2002). Nuclear translocation of proTGFa is induced by various hepatomitogenic stimuli, such as regenerative growth after partial hepatectomy or intoxication with $\mathrm{CCl}_{4}$ and hyperplastic growth induced by $\mathrm{CPA}$ in the intact animal. In culture, the incidence of proTGFo-pos hepatocyte nuclei is elevated by treatment with hepatomitogenic CPA, prostaglandins E2 and F2 $\alpha$, and hepatocyte growth factor (Grasl-Kraupp et al, 2002; Schausberger et al, 2003). Thus, a great variety of growth stimuli all involve nuclear translocation of proTGFo. This peptide may therefore serve as a kind of intracellular shortcut in mediating autocrine growth stimulation of normal, premalignant and malignant liver cells.

The possible interactions of proTGF $\alpha$ with the growth-regulatory machinery in the nucleus of unaltered and (pre)neoplastic hepatocytes are still unclear. Soluble or membrane-bound precursors of TGF $\alpha$ are biologically active, suggesting that the pro-form may attach to the binding site of erbb-1 as known for the mature form (Ignotz et al, 1986). We found that proTGFa and erbb-1 almost always co-localise within the nucleus of mouse hepatocytes, as shown by confocal laser-scanning microscopy (Schausberger $e t a l, 2003)$. It is currently under investigation by FRET technology whether the large TGF $\alpha$ precursor attaches to erbb-1 and may be co-targeted to the nucleus as a receptor-bound ligand. This may provide the clue for the function of this propeptide for DNA synthesis, considering that erbb-1 may act as a transcription factor for cyclin D1 (Lin et al, 2001). Our data also suggest that the activity of proTGF $\alpha$ in the nucleus does not depend on an erbb-1 receptor tyrosine kinase activity, since DNA replication of proTGF $\alpha$-pos nuclei was not affected by the tyrosine kinase inhibitor tyrphostin (Figure 5).

The cell culture system used in the present study allows to investigate the functional significance of nuclear proTGFa in premalignant cells; cultured GSTp ${ }^{+}$hepatocytes showed significantly higher basal rates of DNA replication than $\mathrm{GSTp}^{-}$ hepatocytes. These characteristics closely reflect those described for GSTp ${ }^{+}$cells in the intact liver in vivo. Thus, this defect in growth regulation persists under culture conditions and therefore appears to be independent of intercellular contacts within the intact organ, and of cytokines, growth factors or hormones circulating in the whole body. The present study shows that considerably more GSTp ${ }^{+}$cells synthesise and transport proTGFa to the nucleus than GSTp ${ }^{-}$cells. The nuclear import of this propeptide almost always is followed by DNA replication. The enhanced probability of nuclear translocation of proTGF $\alpha$ may therefore be essential for the intrinsic growth advantage of the preneoplastic cell population. Compared to the current concepts of signal transduction, nuclear proTGF $\alpha$ may not depend on intact erbb-1 receptors on the cell surface. It circumvents the secretion and possible loss of TGF $\alpha$ to the outside of the cell and may confer autonomy and an inherent growth advantage, a pathway preferentially used by the preneoplastic cell population.

In an untreated, healthy liver, almost all of the hepatocytes are in the Go-phase of the cell cycle. In the present study, the incidence of nuclei positive for proTGF $\alpha$ increased in the course of hepatocarcinogenesis. Since proTGF $\alpha$ translocates to the nucleus in the G1-phase of the cell cycle (Grasl-Kraupp et al, 2002), the elevated presence of nuclear proTGF $\alpha$ in (pre)malignant hepatocytes may be evidence for a G1-status of these cells. Several groups reported that premalignant liver cells show an increased expression of c-myc and cyclin D1, known inducers of the transition from G0 to G1 of the cell cylce (Deguchi and Pitot, 1995; Ramljak et al, 2000). On the other hand, the expression of the WAF1/CIP1 gene product, p21 and the c-myc antagonist mad were decreased in hepatocarcinogenesis (Martens et al, 1996). Many growth-stimulating factors exert their activity, provided that the target cell is in the G1-phase of the cell cycle. Thus, the enhanced presence of nuclear proTGFo in the (pre)neoplastic cell compartment appears to be involved in 
the overcoming of critical checkpoints of the cell cycle and in a facilitated response of liver (pre)neoplasia towards various growth stimuli.

Transforming growth factor $\alpha$ and erbb-1 are upregulated in malignancies of many different organs, including HCC. Novel therapeutic approaches have been focusing on the possible benefit of blocking TGF $\alpha$-evoked signal transduction on the cell surface, for example, by erbb-1 blockade (Levitzki and Gazit, 1995; Mendelsohn, 1997). The present study shows that treatment with mature TGF $\alpha$ stimulated DNA synthesis rather in proTGF $\alpha$-neg than in proTGF $\alpha$-pos hepatocytes, which was abrogated by an erbb1-specific tyrosine kinase inhibitor. In $\mathrm{GSTp}^{+}$hepatocytes, however, mature TGF $\alpha$ and tyrphostin exerted no significant effect. Thus, the 'classical' signal transduction pathway of mature TGF $\alpha$ via erbb-1 seems to be active in the unaltered cell population, while the novel pathway seems to operate preferentially in the (pre)malignant cell compartment. It is therefore tempting to speculate that liver tumours may use alternative pathways for growth stimulation by proTGF $\alpha$. Then, they may be resistant against therapeutic strategies targeted at TGF $\alpha$ /erbb-1 interactions on the cell surface.

In conclusion, the present work shows that the incidence of nuclei expressing proTGF $\alpha$ is elevated in the course of rat hepatocarcinogenesis, which may reflect and contribute to the inherent growth advantage of (pre)neoplastic hepatocytes. Further research is necessary to elucidate the mechanisms that regulate the different intracellular routes of $p r o T G F \alpha$ and that may link nuclear proTGF $\alpha$ to DNA replication.

\section{ACKNOWLEDGEMENTS}

The excellent technical assistance of K Bukowska, M Käfer and B Peter is gratefully acknowledged. This study was also supported by 'Herzfeldersche Familienstiftung' and by the Austrian 'Gen-Au Program'.

\section{REFERENCES}

Deguchi T, Pitot HC (1995) Expression of c-myc in altered hepatic foci induced in rats by various single doses of diethylnitrosamine and promotion by $0,05 \%$ phenobarbital. Mol Carcinogen 14: $152-159$

DeGunst MCM, Luebeck EG (1998) A method for parametric estimation of the number and size distribution of cell clusters from observations in a section plane. Biometrics 54: $100-112$

Edmondson HA, Steiner PE (1954) Primary carcinoma of the liver: a study of 100 cases among 48.900 necropsies. Cancer 7: $462-503$

El-Serag HB, Mason AC (1999) Rising incidence of hepatocellular carcinoma in the United States. $N$ Engl J Med 340: 745-750

Fiel MI, Min A, Gerber MA, Faire B, Schwartz M, Thung SN (1996) Hepatocellular carcinoma in long-term oral contraceptive use. Liver 16: $372-376$

Fountoulakis M, Langen H (1997) Identification of proteins by matrixassisted laser desorption ionization-mass spectrometry following in-gel digestion in low-salt, nonvolatile buffer and simplified peptide recovery. Anal Biochem 250: $153-156$

Gerner C, Holzmann K, Grimm R, Sauermann G (1998) Similarity between nuclear matrix proteins of various cells revealed by an improved isolation method. J Cell Biochem 71: 363-374

Grasl-Kraupp B, Bursch W, Ruttkay-Nedecky B, Wagner A, Lauer B, Schulte-Hermann R (1994) Food restriction eliminates preneoplastic cells through apoptosis and antagonizes carcinogenesis in rat liver. Proc Natl Acad Sci USA 91: 9995-9999

Grasl-Kraupp B, Luebeck G, Wagner A, Löw-Baselli A, de Gunst M, Waldhör T, Moolgavkar S, Schulte-Hermann R (2000) Quantitative analysis of tumor initiation in rat liver: role of cell replication and cell death (apoptosis). Carcinogenesis 24: 1411-1421

Grasl-Kraupp B, Ruttkay-Nedecky B, Müllauer L, Taper H, Huber W, Bursch W, Schulte-Hermann R (1997) Inherent increase of apoptosis in liver tumors: implications for carcinogenesis and tumor regression. Hepatology 25: $906-912$

Grasl-Kraupp B, Schausberger E, Hufnagl K, Gerner C, Löw-Baselli A, Rossmanith W, Parzefall W, Schulte-Hermann R (2002) A novel mechanism for mitogenic signaling via pro-transforming growth factor $\alpha$ within hepatocyte nuclei. Hepatology 35: $1372-1380$

Grisham JW (1997) Interspecies comparison of liver carcinogenesis: implications for cancer risk assessment. Carcinogenesis 18: 59-81

Grisham JW (2001) Molecular genetic alterations in primary hepatocellular neoplasms: hepatocellular adenoma, hepatocellular carcinoma, and hepatoblastoma. In The Molecular Basis of Human Cancer Coleman WB, Tsongalis GJ (eds) pp 269-346. Totowa, NJ: Humana Press

Hermank P, Henson DE, Hutter RVP, Sobin HH (1993) A commentary on uniform use. In International Union against Cancer, TNM Supplement 1993 Clark H (ed) pp 33-67. New York: Springer

Ignotz RA, Kelly B, Davis RJ, Massagué J (1986) Biologically active precursor for transforming growth factor type $\alpha$, released by retrovirally transformed cells. Proc Natl Acad Sci USA 83: 6307-6311

International Working Party (1995) Terminology of nodular hepatocellular lesions. Hepatology 22: $983-993$
Kiss A, Wang NJ, Xie JP, Thorgeirsson SS (1997) Analysis of transforming growth factor (TGF)-alpha/epidermal growth factor receptor, hepatocyte growth factor/c-met, TGF- $\beta$ receptor type II, and p53 expression in human hepatocellular carcinomas. Clin Cancer Res 3: 1059-1066

Levitzki A, Gazit A (1995) Tyrosine kinase inhibition: an approach to drug development. Science 267: $1782-1788$

Lin SY, Makino K, Xia W, Matin A, Wen Y, Kwong KY, Bourguignon L, Hung MC (2001) Nuclear localization of EGF receptor and its potential new role as a transcription factor. Nat Cell Biol 3: 802-808

Löw-Baselli A, Huber W, Käfer M, Bukowska K, Schulte-Hermann R, GraslKraupp B (2000a) Failure to demonstrate chemoprevention by the monoterpene perillyl alcohol during early hepatocarcinogesis: a cautionary note. Carcinogenesis 21: 1869-1877

Löw-Baselli A, Hufnagl K, Parzefall W, Schulte-Hermann R, Grasl-Kraupp B (2000b) Initiated rat hepatocytes in primary culture: a novel tool to study alterations in growth control during the first stage of carcinogenesis. Carcinogenesis 21: 79-86

Martens U, Lennartsson P, Hogberg J, Stenius U (1996) Low expression of the WAF1/CIP1 gene product p21 in enzyme-altered foci induced in rat liver by diethylnitrosamine and phenobarbital. Cancer Lett 104: $21-26$

Massagué J (1990) Transforming growth factor $\alpha$. A model for membraneanchored growth factors. J Biol Chem 265: 7709-7712

Mead JE, Fausto N (1989) Transforming growth factor $\alpha$ may be a physiological regulator of liver regeneration by means of an autocrine mechanism. Proc Natl Acad Sci USA 86: 1558-1562

Mendelsohn J (1997) Epidermal growth factor receptor inhibition by a monoclonal antibody as anticancer therapy. Clin Cancer Res 3: $2703-2707$

Miller RT, Cattley RC, Marsman DS, Lyght O, Popp JA (1995) TGF $\alpha$ is differentially expressed in liver foci induced by diethylnitrosamine initiation and peroxisome proliferator promotion. Carcinogenesis 16: $77-82$

Nair S, Mason A, Eason J, Loss G, Perrillo RP (2002) Is obesity an independent risk factor for hepatocellular carcinoma in cirrhosis? Hepatology 36: $150-155$

Ni CY, Murphy MP, Golde TE, Carpenter G (2001) Gamma-secretase cleavage and nuclear localization of ErbB-4 receptor tyrosine kinase. Science 294: 2179-2181

Oberhammer FA, Pavelka M, Sharma S, Tiefenbacher R, Purchio AF, BurschW, Schulte-Hermann R (1992) Induction of apoptosis in cultured hepatocytes and in regressing liver by transforming growth factor $B 1$. Proc Natl Acad Sci USA 89: 5408-5412

Offterdinger M, Schöfer C, Weipoltshammer K, Grunt TW (2002) C-erbB-3: a nuclear protein in mammary epithelial cells. J Cell Biol 157: 929-939

Parkin DM, Bray FI, Devesa SS (2001) Cancer burden in the year 2000. The global picture. Eur J Cancer 37: S4-S66

Parzefall W, Monschau P, Schulte-Hermann R (1989) Induction by cyproterone acetate of DNA synthesis and mitosis in primary 
cultures of adult rat hepatocytes in serum free medium. Arch Toxicol 63: $456-461$

Pitot HC (1990) Altered hepatic foci: their role in murine hepatocarcinogenesis. Annu Rev Pharmacol Toxicol 30: 465-500

Ramljak D, Calvert RJ, Wiesenfeld PW, Divan BA, Catipovic B, Marasas WF, Victor TC, Anderson LM, Gelderblom WC (2000) A potential mechanism for fumonisin $\mathrm{B}(1)$-mediated hepatocarcinogenesis: cyclin D1 stabilization associated with activation of Akt and inhibition of GSK-3beta activity. Carcinogenesis 21: 1537-1546

Schausberger E, Efer R, Parzefall W, Chabicovsky M, Breit P, Wagner EF, Schulte-Hermann R, Grasl-Kraupp B (2003) Induction of DNA synthesis in primary mouse hepatocytes is associated with nuclear pro-transforming growth factor $\alpha$ and erbb-1 and is independent of c-jun. Carcinogenesis 24: $835-841$

Schirmacher P, Schauss D, Dienes HP (1996) Intracellular accumulation of incompletely processed transforming growth factor $\alpha$ polypeptides in ground glass heptocytes of chronic hepatitis B virus infection. J Hepatol 24: $34-44$

Schulte-Hermann R, Timmermann-Trosiener I, Barthel G, Bursch W (1990) DNA synthesis, apoptosis, and phenotypic expression as determinants of growth of altered foci in rat liver during phenobarbital promotion. Cancer Res 50: 5127-5135
Tata JR (1974) Isolation of nuclei from rat liver and other tissues. Methods Enzymol 31: 253-262

Wells A, Marti U (2002) Signalling shortcuts: cell-surface receptors in the nucleus? Nat Rev Mol Cell Biol 3: 1-6

Workman P, Twentyman P, Balkwill F, Balmain A, Chaplin D, Double J, Embleton J, Newell D, Raymond R, S, Stephens T, Wallace J (1998) United Kingdom Co-ordinated Committee on Cancer Research (UKCCCR) Guidelines for the Welfare of Animals in Experimental Neoplasia (2nd Edition). Br J Cancer 77: 1-10

Yamada Y, Yoshimi N, Sugie S, Suzui M, Matsunaga K, Hara A, Mori H (1999) Beta-catenin (Ctnnb1) gene mutations in diethylnitrosamine (DEN)-induced liver tumors in male F344 rats. Jpn J Cancer Res 90: $824-828$

Yamaguchi K, Carr BI, Nalesnik MA (1995) Concomitant and isolated expression of TGF $\alpha$ and EGF-R in human hepatoma cells supports the hypothesis of autocrine, paracrine, and endocrine growth of human hepatoma. J Surg Oncol 58: $240-245$

Yang B, Guo M, Herman JC, Clark DP (2003) Aberrant promoter methylation profiles of tumor suppressor genes in hepatocellular carcinoma. Am J Pathol 163: 1101-1107

Yarden Y, Sliwkowski MX (2001) Untangling the ErbB signalling network. Nat Rev Mol Cell Biol 2: 127-137 